\title{
SPECTROSCOPY OF PROTON IMPLANTED GaN
}

\author{
M.G. Weinstein, ${ }^{*}$ M. Stavola, ${ }^{*}$ C.Y. Song, ${ }^{*}$ C. Bozdog, ${ }^{*}$ H. Przbylinska, ${ }^{*}$ G.D. Watkins, ${ }^{*}$ \\ S.J. Pearton, ${ }^{* *}$ and R.G Wilson,+ \\ *Dept. of Physics, Lehigh University, Bethlehem, Pennsylvania 18015 \\ **University of Florida, Dept. of Materials Science, Gainesville, Florida 32611 \\ +Consultant, Stevenson Ranch, California 92065
}

Cite this article as: MRS Internet J. Nitride Semicond. Res. 4S1,G5.9 (1999)

\begin{abstract}
$\underline{\text { Abstract }}$
Vibrational spectroscopy, photoluminescence, and optically detected electron paramagnetic resonance (ODEPR) have been used to characterize the defects produced in undoped and $\mathrm{Si}$ doped GaN by the implantation of hydrogen. Several new vibrational bands were found near $3100 \mathrm{~cm}^{-1}$ in $\mathrm{GaN}$ that had been implanted with protons. These frequencies are close to those predicted for $\mathrm{V}_{\mathrm{Ga}}-\mathrm{H}_{\mathrm{n}}$ complexes, leading to the tentative assignment of the new lines to $\mathrm{V}_{\mathrm{Ga}}$ defects decorated with different numbers of $\mathrm{H}$ atoms. The proton implantation also produces an infrared PL band centered at $0.95 \mathrm{eV}$ and the ODEPR spectrum labeled LE1, both of which were seen previously for electron-irradiated GaN.
\end{abstract}

\section{Introduction}

The III-V nitrides have eclipsed alternative wide bandgap semiconductors for optoelectronic device applications in the near UV and visible and show promise for high temperature/power electronics. ${ }^{1-3}$ These successes have depended, in part, on an improved understanding and control of defect processes such as the hydrogen passivation of acceptors in the nitrides. ${ }^{4-7}$ Of particular interest here are recent studies of the interaction of hydrogen with native defects ${ }^{8}$ and experimental results for the defects introduced in $\mathrm{GaN}$ by high-energy electron irradiation. ${ }^{9,10}$ In this paper we report results for the defects introduced by the implantation of hydrogen into GaN. The defects created by the implantation that are decorated by $\mathrm{H}$ have been studied by vibrational spectroscopy. PL and ODEPR spectra have been measured for the same H-implanted samples and compared with recent results obtained for GaN irradiated with $2.5 \mathrm{MeV}$ electrons. ${ }^{9,10}$

\section{$\underline{\text { Experimental }}$}

The $2.5 \mu \mathrm{m}$ thick GaN samples used in our experiments were grown by metalorganic chemical vapor deposition (MOCVD) on sapphire substrates at $1040^{\circ} \mathrm{C}$ using trimethylgallium and ammonia. Nominally undoped layers had n-type background concentrations of $\sim 5 \times 10^{16}$ $\mathrm{cm}^{-3}$. A Si-doped sample contained an n-type carrier concentration of $\sim 5 \times 10^{18} \mathrm{~cm}^{-3}$. Protons (and/or deuterons) were implanted at five different energies between 25 and $300 \mathrm{keV}$ in order to create hydrogen profiles with concentrations in the mid $-10^{19} \mathrm{~cm}^{-3}$ range to a depth of $\sim 2.1 \mu \mathrm{m}$. Annealing was performed in flowing $\mathrm{N}_{2}$ at temperatures between $300^{\circ} \mathrm{C}$ and $700^{\circ} \mathrm{C}$. Absorption measurements were made at both normal incidence and by multiple internal reflection so that light polarizations both parallel and perpendicular to the c-axis of the epilayer could be studied. Infrared absorption spectra were measured for the range $1800-4000 \mathrm{~cm}^{-1}$ with a Bomem DA.3 Fourier transform spectrometer equipped with an InSb detector. The measurements were made near $4.2 \mathrm{~K}$ with a resolution of $2 \mathrm{~cm}^{-1}$. Luminescence was excited with the $351 \mathrm{~nm}$ line of an Arion laser. PL in the infrared was detected with a North Coast Ge detector and PL in the visible 


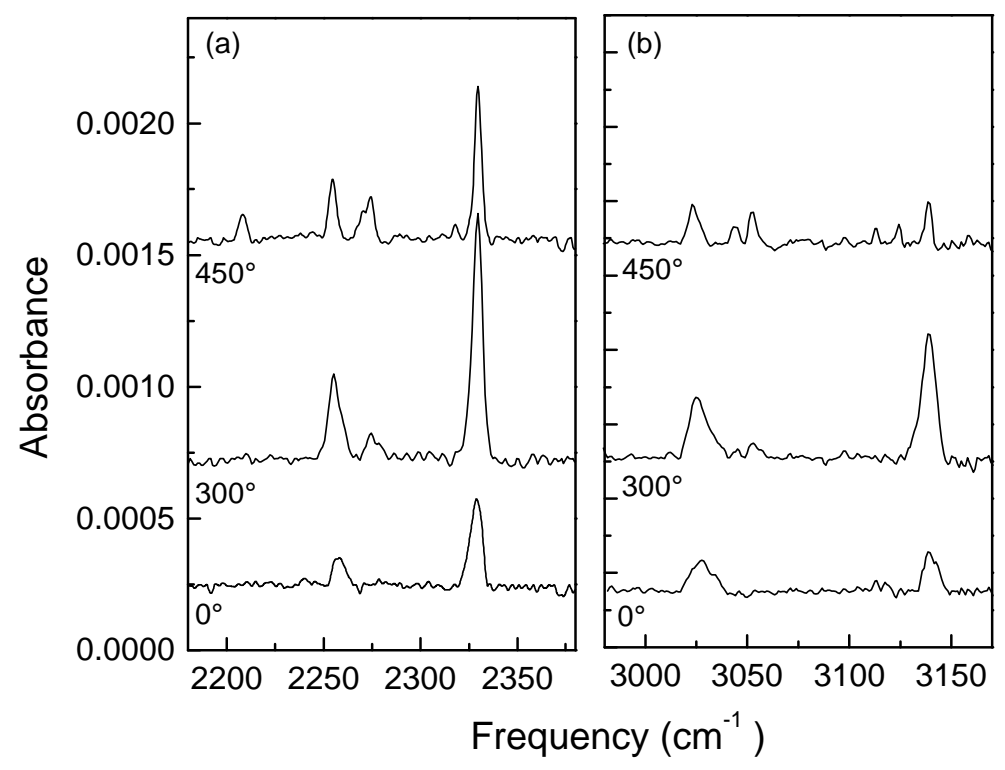

Fig 1. Vibrational spectra measured near $4.2 \mathrm{~K}$ for (a) deuteriumimplanted $\mathrm{GaN}$ and (b) hydrogen-implanted GaN samples which were subsequently annealed at the temperatures indicated.

was detected with a UV-extended Si detector. ODEPR spectra were recorded with a $35 \mathrm{GHz}$ spectrometer at $1.7 \mathrm{~K}$.

\section{Vibrational Spectroscopy}

Spectra are shown in Fig. 1(a) for an undoped GaN sample that had been implanted with deuterium and then annealed at successively higher temperatures. In as-implanted samples, two new vibrational bands were found at $2254.7 \mathrm{~cm}^{-1}$ and $2329.7 \mathrm{~cm}^{-1}$. In the samples implanted with hydrogen [Fig. 1(b)], two corresponding lines were found at $3139.5 \mathrm{~cm}^{-1}$ and $3023 \mathrm{~cm}^{-1}$. Upon annealing, several weaker bands emerge in both the $\mathrm{H}$ - and D-implanted samples. The frequency ratios of the two sets of vibrational lines are near 1.344 , i.e., close to $\sqrt{ }\left(\mathrm{m}_{\mathrm{D}} / \mathrm{m}_{\mathrm{H}}\right)$, confirming that these are hydrogen vibrations. The $\mathrm{H}$ and $\mathrm{D}$ modes of corresponding defects were identified and are listed together in Table I. (Two weak D modes were not well resolved and are not listed.) Spectra were also measured for Si-doped samples $\left(\mathrm{N}_{\mathrm{D}}=5 \times 10^{18} \mathrm{~cm}^{-3}\right)$ that had been implanted with $\mathrm{H}$ or $\mathrm{D}$. The same vibrational bands were seen in these samples, but

Table I. Frequencies of vibrational bands observed in GaN that was implanted with $\mathrm{H}$ or D. The bands are divided into three groups, each of which shows similar behavior upon annealing. The frequency ratio $\mathrm{r} \equiv \omega_{\mathrm{H}} / \omega_{\mathrm{D}}$ and the annealing temperatures where the band intensities are reduced to $\sim 50 \%$ of their maximum value are given.

\begin{tabular}{c|cccc}
\hline Group & $\begin{array}{c}\omega_{H} \\
\left(\mathrm{~cm}^{-1}\right)\end{array}$ & $\begin{array}{c}\omega_{D} \\
\left(\mathrm{~cm}^{-1}\right)\end{array}$ & $r$ & $\begin{array}{c}T \\
\left({ }^{\circ} \mathrm{C}\right)\end{array}$ \\
\hline III & 2982.8 & 2208.4 & 1.351 & 675 \\
I & 3023.1 & 2254.7 & 1.341 & 450 \\
II & 3043.5 & 2270.5 & 1.340 & 550 \\
II & 3052.0 & 2274.5 & 1.342 & 550 \\
II & 3112.8 & 2318.0 & 1.343 & 550 \\
II & 3124.3 & ------- & ------ & 550 \\
I & 3139.5 & 2329.7 & 1.348 & 450 \\
II & 3150.5 & ------ & ------ & 550 \\
\hline
\end{tabular}


were shifted by $\sim 2 \mathrm{~cm}^{-1}$, presumably due to different amounts of strain in the layers. Thus the centers shown in Fig. 1 do not involve $\mathrm{Si}$ impurities that might have been introduced unintentionally in the undoped GaN samples.

Spectra were also measured for an undoped sample which had been implanted with overlapping profiles of both $\mathrm{H}$ and $\mathrm{D}$ to probe whether any of these vibrational bands might be due to defects which contain more than one hydrogen atom. (Additional vibrational lines can appear for multi-H centers when complexes are formed that contain both $\mathrm{H}$ and D). ${ }^{11}$ No additional lines were observed in the spectra for these samples.

Fig. 2 shows the annealing behavior of several of the vibrational bands. Comparing Fig. 2(a) to 2(b), one can see that the bands we have assigned to $\mathrm{H}$ and D modes of corresponding defects, show similar annealing behavior, supporting the associations we have made. Furthermore, the bands can be divided into three groups as indicated in Table I. Group I vibrational bands are strong in the as-implanted samples and reduced to $50 \%$ of their maximum by an anneal at $450^{\circ} \mathrm{C}$. The group II bands begin to grow in at $\sim 300^{\circ} \mathrm{C}$, and then decay to $50 \%$ of their maximum intensity near $550^{\circ} \mathrm{C}$. There is a single band labeled group III that grows in near $450^{\circ} \mathrm{C}$ and then decays to half its maximum intensity near $675^{\circ} \mathrm{C}$. (In the D-implanted sample, the intensity of this lowest frequency band at $2208.4 \mathrm{~cm}^{-1}$ was easy to follow for the different annealing temperatures. However, in the $\mathrm{H}$ implanted samples, the band at $2982.8 \mathrm{~cm}^{-1}$, though seen consistently in samples annealed at $450^{\circ}$ and above, was relatively weak and its intensity could not be characterized quantitatively.)

Vibrational frequencies have been calculated by Van de Walle for $\mathrm{V}_{\mathrm{N}}-\mathrm{H}$ and $\mathrm{V}_{\mathrm{Ga}}-\mathrm{H}_{\mathrm{n}}$ complexes in GaN. ${ }^{8}$ The predicted frequencies are $3100 \mathrm{~cm}^{-1}$ for $\mathrm{V}_{\mathrm{Ga}}-\mathrm{H}$ and $3470 \mathrm{~cm}^{-1}$ for $\mathrm{V}_{\mathrm{Ga}^{-}}$ $\mathrm{H}_{4}$ and are close to the vibrational frequencies we have measured. Van de Walle also predicted a frequency of $600 \mathrm{~cm}^{-1}$ for the $\mathrm{V}_{\mathrm{N}}-\mathrm{H}$ complex, ${ }^{8}$ much lower than the vibrational frequencies we have seen. Therefore, comparison with theory leads us to suggest that the lines we have observed correspond to nitrogen-dangling-bond defects that are decorated by hydrogen. The vibrational frequencies we have measured are also close to the frequency observed previously for the passivated $\mathrm{Mg}$ acceptor in $\mathrm{GaN}\left(3125 \mathrm{~cm}^{-1}\right){ }^{5}$ where the $\mathrm{H}$ is believed to be bonded to one of the $\mathrm{Mg}$ atom's neighbor $\mathrm{N}$ atoms. ${ }^{5-7}$ Additional evidence that an $\mathrm{N}-\mathrm{H}$ stretching mode is being observed comes from the isotopic frequency ratio $r \equiv \omega_{H} / \omega_{D}$ which is sensitive to the atom to which the hydrogen is attached. For the vibrational lines observed in H- and D- implanted GaN,

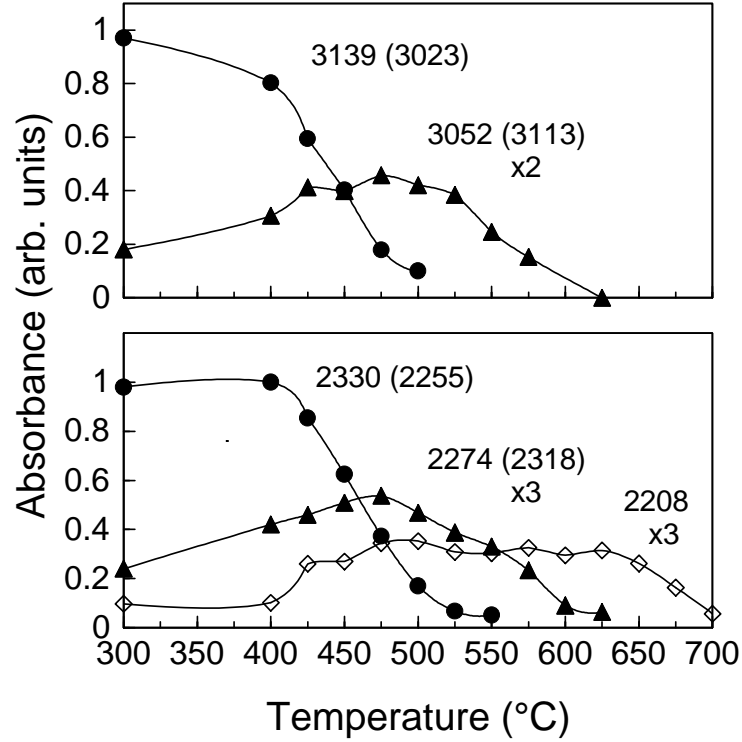

Fig 2. The intensities of selected absorption lines vs. annealing temperature for $\mathrm{GaN}$ samples that were implanted with hydrogen (a) and deuterium (b). The frequency of the band for each set of data is shown. The frequencies given in parentheses are for bands with annealing behavior very similar to the ones shown. (Curves are shown to guide the eye.) 
$\mathrm{r}=1.344$ (the average of the values reported in Table I) which is very close to the ratio previously reported for the $\mathrm{Mg}-\mathrm{H}$ complex in $\mathrm{GaN}, \mathrm{r}=1.346,{ }^{5}$ where the $\mathrm{H}$ is believed to bonded to N. Further, these ratios are smaller than those reported previously for $\mathrm{Ga}-\mathrm{H}$ bonds in $\mathrm{H}$ implanted GaAs where $r \approx 1.39,{ }^{12}$ further confirming that the new lines observed near $3100 \mathrm{~cm}^{-1}$ in $\mathrm{GaN}$ can be associated with $\mathrm{N}-\mathrm{H}$ bonds.

The annealing behavior of the defects we have observed in $\mathrm{H}$-implanted GaN is similar to that of defects seen previously in H-containing InP. In as-grown ${ }^{13-15}$ and $\mathrm{H}$-implanted ${ }^{16}$ InP there is a strong band at $2316 \mathrm{~cm}^{-1}$ that has been assigned to a $\mathrm{P}-\mathrm{H}$ stretching mode of a $\mathrm{V}_{\text {In }}-\mathrm{H}_{4}$ complex. ${ }^{14,15,17}$ A lower frequency band at $2201 \mathrm{~cm}^{-1}$ has also been assigned to a P-H stretching mode of $\mathrm{V}_{\mathrm{In}}-\mathrm{H} .^{14,17,18}$ Additional weak lines have been seen between these frequencies. ${ }^{14,16}$ Ewels et al ${ }^{17}$ have calculated the frequencies of the $\mathrm{V}_{\mathrm{In}}-\mathrm{H}_{\mathrm{n}}$ complexes and have proposed that the partial dissociation of the $\mathrm{V}_{\text {In }}-\mathrm{H}_{4}$ complex upon annealing leads to the formation of $\mathrm{V}_{\text {In }}-\mathrm{H}_{\mathrm{n}}$ centers with fewer $\mathrm{H}$ atoms, and thus lower frequencies, to explain the presence of several $\mathrm{H}$ stretching bands. Similarly, in our GaN studies, we suggest that the N-H stretching modes we observe belong to a family of $\mathrm{V}_{\mathrm{Ga}}-\mathrm{H}_{\mathrm{n}}$ complexes. We therefore tentatively assign the highest frequency band at $3139.5 \mathrm{~cm}^{-1}$ to a $\mathrm{V}_{\mathrm{Ga}}-\mathrm{H}_{4}$ complex. The evolution of the spectrum upon annealing would therefore be due to the successive, partial dissociation of the $\mathrm{V}_{\mathrm{Ga}}-\mathrm{H}_{\mathrm{n}}$ centers and thus the weaker lines at lower frequency are due to $\mathrm{V}_{\mathrm{Ga}}-\mathrm{H}_{\mathrm{n}}$ complexes with fewer than four $\mathrm{H}$ atoms. Further support for such a scheme comes from the calculations of Van de Walle who found that the binding energy of $\mathrm{H}$ decreases for the $\mathrm{V}_{\mathrm{Ga}}-\mathrm{H}_{\mathrm{n}}$ complexes as $n$ increases. ${ }^{8}$

This assignment of the hydrogen-stretching bands and their annealing behavior appears not to be supported by our results for the GaN samples that had been co-implanted with $\mathrm{H}$ and $\mathrm{D}$ because additional lines due to centers that may contain both hydrogen isotopes were not observed. Results for $\mathrm{V}_{\mathrm{In}}-\mathrm{H}_{\mathrm{n}}$ complexes in InP provide further guidance here. In a previous study of $\mathrm{H}$ and $\mathrm{D}$ implanted InP, similar results were obtained and no line splittings were observed, ${ }_{14}^{16}$ even though the line observed at $2316 \mathrm{~cm}^{-1}$ has been assigned to a $\mathrm{V}_{\text {In }}-\mathrm{H}_{4}$ complex. ${ }^{14,15,17}$ It was found later that in samples where $\mathrm{H}$ and D had been introduced during growth (which gives rise to much sharper lines), the $2316 \mathrm{~cm}^{-1}$ band was split into a triplet by the presence of both $\mathrm{H}$ and $\mathrm{D}$, but with a line splitting of only $\sim 0.5 \mathrm{~cm}^{-1}$, too small to have been observed in the implanted samples. ${ }^{15}$ The line widths in our proton implanted GaN samples are $\sim 5 \mathrm{~cm}^{-1}$ which would also prevent the observation of such small line splittings. Thus, if the situation in $\mathrm{GaN}$ is similar to that proposed previously for $\mathrm{InP},{ }^{15}$ the lack of line splittings upon

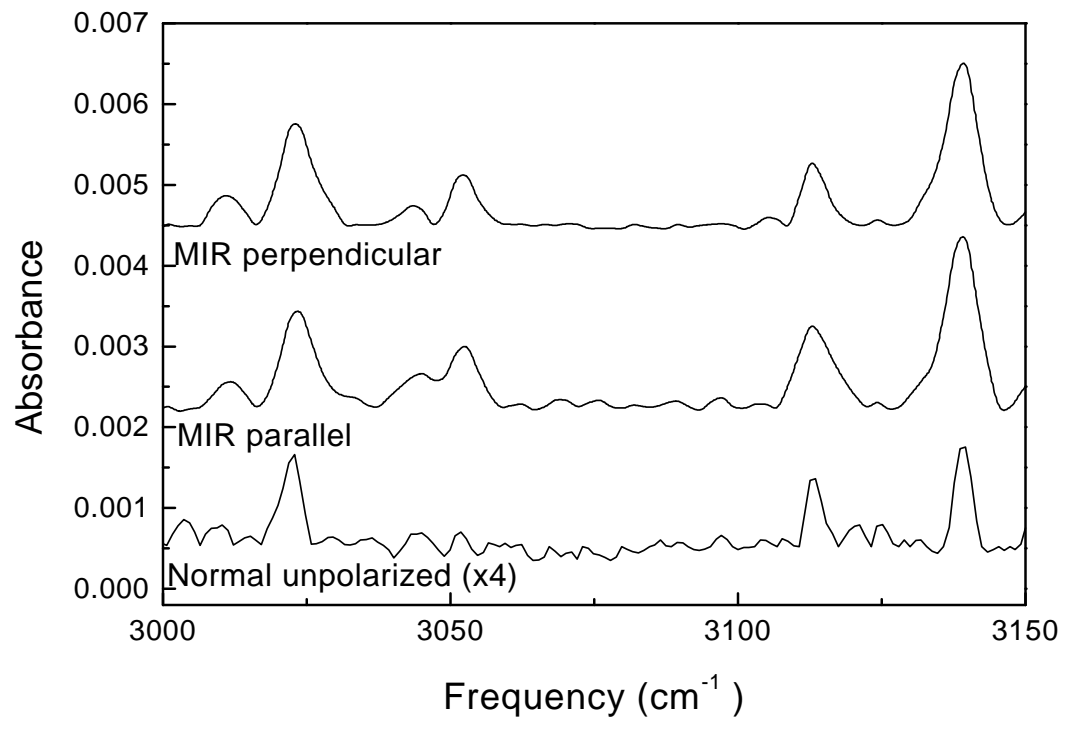

Fig. 3. Vibrational spectra measured by multiple internal reflection for the polarization parallel to the plane of the sample or the perpendicular polarization with a component normal to the epitaxial layer. Also shown for comparison is a spectrum measured with the light beam (unpolarized) at normal incidence to the epitaxial layer. 
the coimplantation of $\mathrm{H}$ and $\mathrm{D}$ in our experiments on $\mathrm{GaN}$ does not rule out the assignments for the H-stretching bands we have suggested above.

The infrared measurements described up to this point were measured with the probing light normal to the sample where the polarization of the light must be in the plane of the epitaxial layer (i.e., the a-b plane of the wurtzite $\mathrm{GaN}$ ). Therefore, vibrational modes that might have their transition-dipole moments perpendicular to the layer (i.e., along the c-axis for $\mathrm{GaN}$ ) cannot be excited. To investigate the possibility that there might be a preferential alignment of the hydrogen-implantation-related defects in the wurtzite lattice, the ends of the sapphire substrate were beveled at $45^{\circ}$ to fabricate a multiple-internal-reflection (MIR) prism. Spectra measured for normal incidence and by MIR with in- and out-of- plane polarizations are compared in Fig. 3. Although the MIR geometry increased the signal to noise ratio of the measurements, no significant difference was observed between the different polarizations. This result suggests that none of the defects introduced by the proton implantation that we observe by vibrational spectroscopy are preferentially aligned along the c-axis of the wurtzite $\mathrm{GaN}$ or that any possible line splittings for different defect orientations are too small to be resolved in our experiments. Similarly, Clerjaud et al. have reported that for $\mathrm{Mg}-\mathrm{H}$ complexes in p-type GaN, there was no difference observed for spectra measured by MIR for different polarizations of the exciting light. ${ }^{7}$

\section{Photoluminescence and ODEPR}

Nominally undoped GaN samples have been examined by PL and ODEPR before and after the implantation of hydrogen. The as-grown samples show the strong $2.2 \mathrm{eV}$ yellowluminescence band and the ODEPR spectra previously attributed to the dominant donor and a deep defect that are seen in GaN [Fig. 4(a)]. ${ }^{19}$ The implantation of hydrogen into our samples greatly reduced the intensity of the yellow luminescence. The implantation also produced a near infrared luminescence band centered at $\sim 0.95 \mathrm{eV}$, very similar to a band reported previously that is produced by high-energy electron irradiation., ${ }^{9,20}$ The near-infrared PL spectra seen for electron-irradiated and proton-implanted samples are compared in Fig. 5.

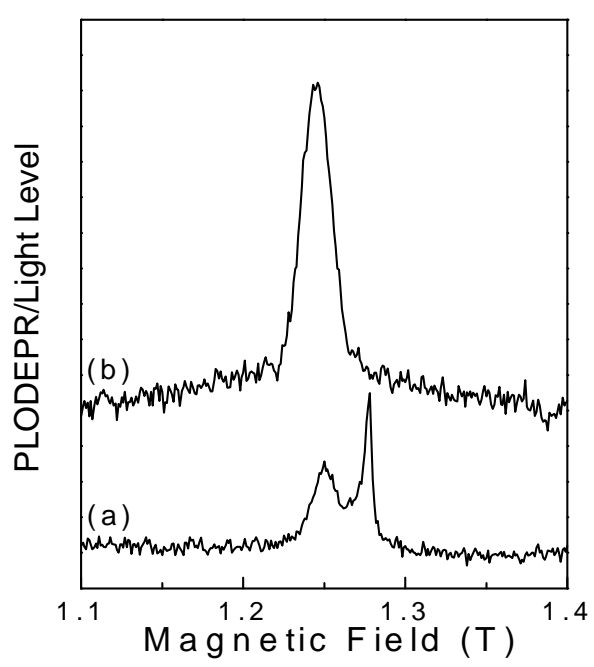

Fig 4. PLODEPR spectra in (a) as-grown, undoped GaN, observed in the $2.2 \mathrm{eV}$ PL band and (b) following $\mathrm{H}$-implantation observed in the IR PL band

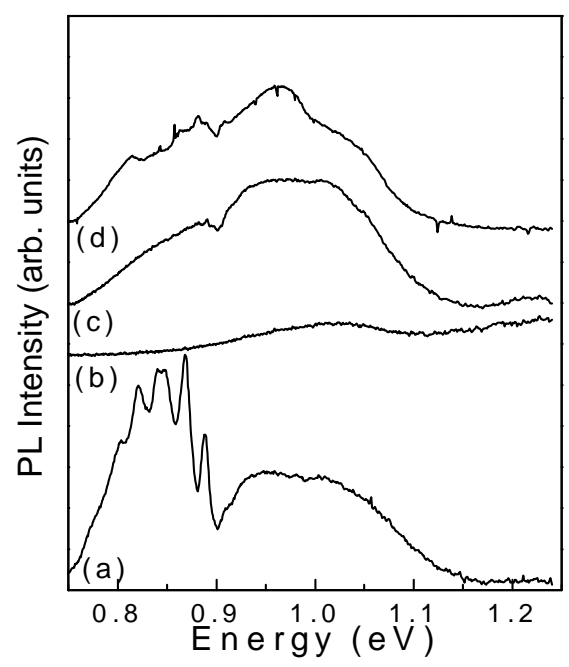

Fig. 5. PL in the IR for (a) an electron-irradiated GaN sample $\left(2.5 \mathrm{MeV}, 1.5 \times 10^{18} \mathrm{e} / \mathrm{cm}^{2}\right)$; an undoped GaN sample (b) before and (c) after $\mathrm{H}$ implantation; and (d) an additional $\mathrm{H}$-implanted sample. 
In the previous results for electron-irradiated samples [Fig. 5(a)], a broad, structureless band ranging from $\sim 0.75$ to $1.1 \mathrm{eV}$ with its peak at $0.95 \mathrm{eV}$ was observed. A sharply structured band to the low energy side of this broad band was also produced. Proton implantation also produced the broad $0.95 \mathrm{eV}$ band (spectra b-d). In one proton-implanted sample (spectrum d), the sharply structured band was seen, but only weakly; in other samples this band was not observed.

Electron-irradiated GaN shows several new ODEPR spectra labeled LE1-LE4 associated with the near-IR luminescence. ${ }^{9,10}$ Our proton implanted samples show only the $S=1 / 2$ spectrum LE1 [Fig 4(b)]. Spectrum LE2, associated with the more sharply structured luminescence band, and the two ODEPR spectra attributed to displaced $\mathrm{Ga}$ atoms were not seen in our protonimplanted samples. At present, the defects responsible for the near-IR photoluminescence and associated ODEPR spectra have not been identified. Nonetheless, the defects created by proton implantation give similar spectroscopic signatures, making the electron-irradiation results an interesting baseline with which to compare the defects that result from ion implantation.

The work at LU was supported by ONR Grant No. N00014-94-1-0117. The work at UF was partially supported by NSF Grant No. DMR 9421109.

1. F.A. Ponce and D.P. Bour, Nature 386, 351 (1997).

2. GaN and Related Materials, edited by S.J. Pearton (Gordon and Breach, Amsterdam, 1997).

3. Gallium Nitride (GaN), edited by J. Pankove and T.D. Moustakas (Academic, Boston, 1997).

4. S. Nakamura, N. Iwasa, M. Senoh, and T. Mukai, Jpn. J. Appl. Phys. 31, 1258 (1992).

5. W. Götz, N.M. Johnson, D.P. Bour, M.D. McCluskey, and E.E. Haller, Appl. Phys. Lett. 69, 3725 (1996).

6. J. Neugebauer and C.G. Van de Walle, Phys. Rev. Lett. 75, 4452 (1995).

7. B. Clerjaud, D. Côte, and A. Lebkiri, Proceedings $8^{\text {th }}$ International Conference on Shallow-Level

Centers in Semiconductors, Phys. Stat. Sol. (b) 210, (1998), to be published.

8. C.G. Van de Walle, Phys. Rev. B 56, R10020 (1997).

9. M. Linde, S.J. Uftring, G.D. Watkins, V. Härle and F. Scholz, Phys. Rev. B 55, 10177 (1997).

10. G.D. Watkins, M. Linde, P.W. Mason, H. Przybylinska, C. Bozdog, S.J. Uftring, V. Härle, F.

Scholz, W.J. Choyke and G.A. Slack, Defects in Semiconductors, ICDS-19, edited by G. Davies and M.H. Nazaré (Trans Tech, Switzerland, 1997), p. 1087.

11. M. Stavola, Identification of Defects in Semiconductors, edited by M. Stavola (Academic,

Boston, 1999), vol. 51B, p. 153.

12. B. Pajot, J. Chevallier, A. Chaumont, and R. Azoulay, Defects in Electronic Materials, edited by

M. Stavola, S.J. Pearton, and G. Davies (Mat. Res. Soc., Pittsburgh, 1988), p. 345.

13. R.C. Newman, Semicond. Sci. Technol. 5, 911 (1990).

14. R. Darwich, B. Pajot, B. Rose, D. Robein, B. Theys, R. Rahbi, C. Porte, and F. Gendron, Phys.

Rev. B 48, 17776 (1993).

15. F.X. Zach, E.E. Haller, D. Gabbe, G. Iseler, G.G. Bryant, and D.F. Bliss, J. Electron. Mat. 25, 331 (1996).

16. D.W. Fischer, M.O. Manasreh, and G. Matous, J. Appl. Phys. 71, 4805 (1992).

17. C.P. Ewels, S. Öberg, R. Jones, B. Pajot, and P.R. Briddon, Semicond. Sci. Technol. 11, 502 (1996).

18. B. Clerjaud, D. Côte, and C. Naud, Phys. Rev. Lett. 58, 1755 (1987).

19. E.R. Glaser, T.A. Kennedy, K. Doverspike, L.B. Rowland, D.K. Gaskill, J.A. Freitas, M. Asaaf-

Khan, D.T. Olson, J.N. Kuznia, W.K. Wickenden, Phys. Rev. B 51, 13326 (1995).

20. I.A. Buyanova, Mt. Wagner, W.M. Chen, B. Monemar, J.L.. Lindström, H. Amano, and I.

Akasaki, Appl. Phys. Lett. 73, 2968 (1998). 